\title{
Continuing professional development for English language teachers in digital era
}

\author{
Irwandi ${ }^{1}$, Albert $^{2}$ \\ ${ }^{12}$ Institut Agama Islam Negeri, Bukittinggi, Indonesia, (irwandimalin@gmail.com)
}

\begin{abstract}
English language teacher strives to raise standards of language teaching in the new global setting knowledge. Perhaps understandably, any efforts to improve language education quality cannot succeed without the continuous support and cooperation of a professional teacher. This fact is widely recognized in international attention mostly in term of promoting the continuing professional of teachers. The term of continuing refers to the need for ongoing development of teachers' knowledge, professional skill, and their effectiveness in the classroom. This is a reaction to the professional development which is not satisfied yet in leading to an increase in teacher knowledge, skills, and commitment. This paper explores the concept of continuing professional development, the limitation of current approaches to professional development, and the reinvigoration strategy of professional development for English language teacher.
\end{abstract}

Keywords: professional development, continuing professional development, english teacher

\section{Introduction}

One of the challenges in improving English language education quality is how English language teachers can be given a professional development to enable them to respond a change in a teacher's practice that leads to increase learner's academic achievement. The professional development for English language teacher is accepted as one of instruments to improve English teaching quality and student achievement. It is also considered as an effort to introduce curriculum and pedagogical reforms(Carr, et al., 2000). To improve its quality, some guidelines are promoted to support planners and developers of professional development to understand the criteria of effective professional development and strategies (Lieberman and Miller, 2008). Effective professional development needs to be sustained over time through intensive learning experiences and contextualized. This can be implemented through on-going types of learning and ample time period.

This paper focuses explores the concept of continuing professional development, the limitation of current approaches to professional development, and the reinvigoration strategy of language teacher professional development. The concern is on teachers rather than school leaders, but the implications are highlighted for school leadership and management. 


\section{Discussion}

The Professional Development for English Teacher

The professional development for teachers nowadays relates to the key term of continuing which appears as a response on the need for ongoing development of teachers' knowledge and professional skills. This is a must for English teachers in order to lead them as effective teachers in today's school. Moreover, the education system internationally strives to raise the level of student achievement and school quality. This effort leads to the restructuration and changing at all levels, including school monitoring and teacher performance. The appearance of new form of pedagogy or new subjects in the digital era also triggers the need for continuing professional development for English teachers.

As a main focus of professional development for English teacher learning is influenced by the characteristics of teacher in the context of individual learner, the place he/she works (organizational context), and educational policy as the external context. The various factors depend on theoretical perspective adopted, for instance the theory which views professional development is conducted in the context of career development or as something that is promoted by the institution in which the teacher works (Guskey and Huberman, 1995). Some factors that influence teacher learning are elaborated as follows:

1. Characteristics of the individual learner

Learning is not an automatic process since a decision to learn depends on individual effort, commitment, and mentality in responding a failure. Each person also has learning style which is different from others. Moreover, individual development need is also shaped by factors as length of career experience, gender, and cultural background.

2. The organizational context

Teachers' environment is unforgettable factor in affecting their response on professional development activity. In this context, culture and ethos of school, quality of leadership and bureaucracy, and availability of resources will determine significantly on teachers' opportunity and motivation to devote to their professional development. It is suggested that school leaders can demonstrate their real supporting on teacher professional development.

The tangible evidence of school supporting on the professional development can be indicated through teacher's need assessment. The result of need assessment determines the model of professional development for teacher. Moreover, some indicators for school which supports professional development for teacher encompassing: having procedure for assessing teacher need, providing the chance for teacher to follow professional development, appraising teacher professionalism, leading teacher to become reflective teacher, and motivating teacher for being innovative person.

3. The external context

This aspect especially refers to educational policy on the status of teaching profession. The policy may encompass the system of teacher recruitment and retention, salary, hours of work, and level of professional development. Theseinevitably determine job satisfaction and teacher quality.

The professional development for teacher also needs to apply 5 (five) important principles of teacher professional development (Gulamhussein, 2013). These principles include: 1. The professional teacher development duration should be significant and ongoing to allow teachers to learn new strategies and struggle with issues when they are implemented. 2 . There should be a support for teachers during the implementation phase of new strategies that have their own challenges in practicing in the classroom. 3. The initial presentation of the concept to be proposed to teachers should actively involve the teacher. 4. Modeling is more effective in helping teachers to 
practice new strategies. 5. The training materialswhich are presented to teachers should not be general, but more specific.

The first principle is based upon the results of the research that professional development which is conducted in a long duration of time will provide a greater impact on the progress of teachers. This happens because the professional development activities with a long duration of time is positively associated with changes in teacher (teacher change) and improvements to the learners' academic achievement education of students (Darling, et al., 2009).

The study on the impact of the professional development program for teachers indicated that 80 hours or more a teacher's professional development activities significantly influence on the change in the teacher's way of teaching less than 80 hours of training (Corcoran, et al., 2003). These findings corroborate the results of research on teacher learning that indicates that the new skill acquisition process requires a considerable time for teachers. Teachers need at least 50 hours of learning, practice, and coaching before a new teaching strategy is mastered and applied in the classroom.

The second principle emphasizes the importance of support for teachers in implementing a new strategy in the classroom. Numerous studies have found that when teachers are given the support during this stage, they can change the way of teaching in the classroom. It is found that teachers who were given an intensive guidance (coaching) are transferable new skills in teaching in the classroom, but teachers who are just attending the workshop will quickly lose interest in such new skills and does not apply them in the classroom (Knight and Cornett, 2009).

The third principle emphasizes that teachers need a comprehensive understanding of a technique and theory before they are applied in the classroom. Then, the fourth principle emphasizes the urgency of modeling. Through modeling, it is easy for the teacher to understand and implement a new strategy in the classroom. The final principle emphasizes the urgency of presentation skills or new strategies to teachers specifically. This principle directsthe professional development for teacher towards concepts and specific skills (Gulamhussein, 2013).

\section{Achieving a Professional Development for English Teachers}

The main core of English teaching is to improve the quality of learner's achievement in learning English. Thus, the improvement of knowledge and skills of English teachers should have implications on the quality leaners' academic achievement. Therefore, the organizer of professional development of teachers of English and the teachers themselves should consider the relevance and impact of the professional development activities towards the learners' academic achievement. The professional development for English teachers ideally should not focus on the basic knowledge of teaching methods. On the contrary, the teachers' professional development in this era requires a change in the teacher's teaching technique which leads to an increase in the learners' academic achievement (Gulanhussein, 2013).

McMahon (2003: 602-603) suggests three trends in relation to the professional development for teachers, namely: standard of professional development practice which is based on factual information (evidence-informed practice), and professional learning communities. These trends can be implemented for the professional development of English teachers. The standards of professional development is aimed at developing standards and procedures for teacher assessment encompassing: the teachers' commitment on the students and their learning; the teacher's knowledge on the subject which is taught and how to teach it, the responsibility of the teacher to manage and monitor the learners' academic achievement, teachers' systemic thinking style on instructional activities, teachers' ability to learn from experience, and the involvement of teachers in the learning communities. These five principles can help the organizer of professional development activities for teachers to specify what the needs of teachers. 
In relation to evidence-informed practice, English teachers are required to be able to conduct an action research which leads them to make a decision in the classroom scientifically. Consequently, any efforts and quality improvements of teaching should be based on factual information which is achieved through the research. This approach has a number of implications for the professional development of English teachers or at least advises the teachers to be more research-oriented approach. Teachers who are accustomed to conduct the research on how they teach will be the information-rich person (Joyce, et al., 1999).

Furthermore, the concept of professional learning communities emphasizes on the development of agreed values and supportive culture in which the teacher involves responsibly for the learner's academic performance. Nowadays, this model of professional development model is adopted by by various countries in the world (MacMahon, 2003). On the other hand, the awareness occurs as well as the presence of the idea that the school as a learning community where teachers collaborate with colleagues, learners, and parents to increase quality of teaching and learning in schools. King and Newman (2001) argue that learning that are occupied by the teacher can occur when the teacher is able to concentrate on teaching and result of performance of learners (student outcomes), has a continuous chance to learn and conduct an experiment, and gain valuable insight about distinctive innovations.

\section{Conclusion}

The continuing professional development for teachers becomes a necessity. A teacher who wants to be an effective teacher should renew their knowledge and skills through ongoing professional development activities. On the other hand, a professional teacher development program that has an impact on student learning are long-lasting and intensive program. Finally, professional teacher development programs that have an impact on student learning are long-lasting and intensive programs.

\section{References}

Carr, M., et al. (2000) . The Effects of Curricula and Assessment on Pedagogical Approaches and on Educational Outcomes. Wellington: Ministry of Education.

Corcoran, T., et al. (2003). Getting it Right: The MISE Appoach to Professional Development. Philadelphia, PA: Consortium for Policy Research in Education.

Darling, Hammond, L., et al. (2009). Professional Learning in the Learning Profession: A Status Report on Teacher Development in the United States and Abroad. Oxford, OH: National Staff Development Councill.

Gulamhussein, Allison. (2013). Teaching the Teachers: Effective Professional Development in an Era of High Stakes Accountability. New York: National School Boards Association.

Guskey, T.R. and Huberman, M. (1995). Professional Development in Education. New York: Teacher's College Press.

Joyce, B., et al. (1999). The New Structure of School Improvement. Buckingham: Open University Press.

Knight, J. \& Cornett, J. (2009). Studying the Impact of Instructional Coaching. Lawrence, KS: Kansas Coaching Project for the Center on Research on Learning.

Lieberman, A. \& Miller, L. (2008). Teachers in Professional Communities. New York: Teachers' College Press.

Mcmahon, Agnes. (2003). “Continuing Professional Development for Teachers". Dalam Handbook of Educational Leadership and Management. Brent Davies dan John West-Burnham (Editor). London: Pearson Education Limited. 
Trusdale, W.T. (2003). The Implementation of Peer Coaching on the Trasnferability of Staff Development to Classroom Practice in Two Selected Chicago Public Elementary School. Dissertation Abstracts International, 64 (11), 3923. University Microfilms No. 3112185. 